\title{
Revisando la historia para emprender nuevos desafíos
}

En la Sociedad de Periodoncia de Chile, en el año 2004, nos propusimos cambiar la orientación de lo que hasta ese año teníamos como órgano de difusión de nuestras actividades, que tenía por nombre "Periodoncia al Día", y decidimos crear un órgano de difusión científica. Con mucha valentía y responsabilidad el directorio de aquel año, aprobó la iniciativa que tenía como dificultad mayor el financiamiento de tan noble idea. Por cierto, la tarea no fue nada fácil, sobre todo con la cultura arraigada que lo nacional es de mediana calidad, y que además coincidía con un escaso desarrollo de la investigación en el área de la periodoncia y en general en la odontología, medido en cifras duras: pocos proyectos de investigación y escasas publicaciones científicas en revistas internacionales asociadas al área.

La discusión en el directorio de la Sociedad se centraba en el financiamiento de este nuevo órgano de difusión científica, de manera tal de establecer si la inversión monetaria tendría un retorno del dinero o sólo sería un gasto, ¿Correspondía que ese fuese el destino del dinero recaudado en la Sociedad producto de las buenas gestiones de previos directorios?, ¿Quién aseguraba que esta iniciativa perduraría en el tiempo y no solo sería un derroche de dinero, que afectaría los recursos de la Sociedad de Periodoncia?

Así creada, con la naciente "Revista Chilena de Periodoncia y Osteointegración" fuimos resolviendo las dificultades del inicio, donde además de lo ya señalado debíamos de sumar la inexperiencia del trabajo como grupo en la gestión de una revista científica, en las tareas periodísticas (Patricio Villablanca), diseño de los trabajos científicos (Alejandra Pozo), construcción de la página web para realizar el sistema de corrección por pares revisores y de la recepción de los trabajos de investigación para posterior envío a revisión a los pares evaluadores (Valeria Ramírez; Carola Maire). Con el trabajo diario, fuimos superando las dificultades y funcionamos desde el año 2004 al año 2007.

Durante el funcionamiento de la "Revista Chilena de Periodoncia y Osteointegración", se suscitó un problema con la Sociedad de Implantología, por el término Osteointegración. La sociedad de Implantología nos hizo ver que ese término había sido inscrito por ellos y que por tanto les pertenecía, y nosotros argumentábamos que un proceso biológico no podía patentarse y que además la Sociedad de Implantología había inscrito el término Oseointegración y no el de Osteointegración que era el que nosotros habíamos incorporado en la Revista.

Después de muchos dolores de cabeza, malos entendidos, enojos, gastos en asesoría con abogados, tuvimos en conjunto otra muy buena idea: ¿Qué tal si nos asociábamos alrededor de este órgano de difusión científica? Lo anterior nos permitía resolver la propiedad del nombre en cuestión, evitando los tribunales y de paso mejorábamos el financiamiento de la revista, con la no menos interesante ventaja de aumentar el espectro de los temas científicos disponibles para ser recepcionados en la revista. Con esta idea en mente, ofrecimos ser parte de esta propuesta de trabajo a varias sociedades científicas, siendo únicamente la Sociedad de Prótesis y Rehabilitación Oral de Chile, la que aceptara este importante desafío.

Es así como, previo a realizar algunos trámites administrativos, entre ellos cambiar el ISSN (número internacional que permite identificar de manera única una colección, evitando el trabajo y posibles errores de transcribir el título o la información bibliográfica pertinente), en el año 2008 dimos vida a la "Revista de Periodoncia, Implantología y Rehabilitación Oral", convirtiéndose desde ese momento en el órgano oficial de difusión científica de la Sociedad de Periodoncia de Chile, Sociedad de Implantología Oral de Chile y de la Sociedad de Prótesis y Rehabilitación Oral de Chile.

Ya con la experiencia de 4 años de trabajo en la revista científica, con el ingreso de dos nuevas sociedades científicas, y la incorporación de la Federación Iberopanamericana de Periodoncia (FIPP) y la Asociación Latinoamericana de Rehabilitación Oral (AILARO) el trabajo se fue haciendo más productivo y, con la incorporación a Scielo (Scientific Electronic Library Online) en marzo del año 2011, nuestra Revista PIRO, fue adquiriendo una visibilidad mayor, además de convertirnos en la primera revista de odontología en Chile, en ser incorporada en esta importante biblioteca científica. Con esto, se suma a nuestro equipo editorial Ilia Silva, bibliotecaria, quien debe realizar la marcación de los artículos para poder subirlos a la plataforma Scielo.

Producto del ingreso en los sistemas de indexación en Scielo, Latindex, Lilacs y Redalyc, es que en el año 2014 la Editorial Elsevier nos ofrece que las gestiones administrativas las hagamos con ellos. Las tres sociedades científicas apoyaron la decisión y de esta manera nos hicimos profesionales en todo el sistema de revisión de pares y envío de manuscrito a PIRO, desafortunadamente al unirnos a esta importante editorial, debimos de prescindir de los servicios profesionales de Patricio Villablanca, Alejandra Pozo y Valeria Ramírez. En una decisión unilateral, en el año 2016, Elsevier nos señala que no puede seguir entregando sus servicios profesionales a nuestra revista, motivo por el cual y, con el fin de continuar con los niveles de profesionalización que llevábamos, comenzamos a trabajar con ScholarOne Manuscripts, del grupo Clarivate Analytics; con quienes mantenemos nuestro trabajo hasta el día de hoy. Actualmente, nuestro equipo de trabajo cuenta con un profesor de idioma inglés (Juan Fernández); fortalecimos y profesionalizamos nuestra página web (Juan Carlos Lagos-Ideagráfica); se reincorporó Alejandra Pozo al diseño de los trabajos y se mantienen llia Silva y Carola Maire.

Con la decisión de los directorios de las Sociedades Científicas de Odontopediatría y de Ortodoncia de incorporarse a la Revista Piro, hecho que formalmente se produce en diciembre del 2016 y enero del 2019, respectivamente, era necesario evaluar en el renovado consejo de la Revista proceder a hacer las consultas a Conicyt si estábamos en condiciones de hacer un cambio en el nombre de la revista. Hechas las consultas de factibilidad hemos procedido dentro de un listado de posibles nombres a efectuar una votación por el nuevo nombre de la revista entre los consejeros de las 5 sociedades científicas y el suscrito, quedando como nuevo nombre de nuestra revista científica: "INTERNATIONAL JOURNAL OF INTERDISCIPLINARY DENTISTRY”.

Es necesario agradecer los esfuerzos y el constante apoyo que siempre hemos tenido de las Sociedades de Implantología, Rehabilitación Oral, y Periodoncia, y también a las Sociedades de Odontopediatría y Ortodoncia, por la decisión de sus directorios, en una decisión que significa concentrar esfuerzos en una nueva revista científica que será el órgano de difusión para las 5 sociedades y además con la necesidad de aportar recursos económicos para el funcionamiento de la revista. Deseo además aprovechar esta oportunidad para saludar a todas las empresas que nos han acompañado en la revista contribuyendo al financiamiento, sobre todo a aquellas que lo hacen desde el año 2004 (Colgate Palmolive S.A.).

El correcto y armónico desarrollo de "INTERNATIONAL JOURNAL OF INTERDISCIPLINARY DENTISTRY", requiere que tomemos decisiones que nos permitan mirar con tranquilidad el proceso de instalación de la revista en el ámbito nacional e internacional. Desde el año 2004, la Sociedad de Periodoncia ha sido el lugar desde donde hemos realizado el trámite administrativo de la gestión económica de la revista, y debemos de decidir si seguimos en esa modalidad o bien creamos una estructura diferente. La gestión económica para el financiamiento y para la generación de recursos extras para la implementación de sistemas de modernización de la gestión debe ser desarrollada por un equipo diferente a quiénes desarrollamos la gestión científica. La buena situación actual del aumento tanto cuantitativo como cualitativo ya sea en la obtención de proyectos de investigación como de publicaciones científicas que ha ocurrido en nuestro país debe de complementarse con el compromiso de los(as) investigadores de publicar en "INTERNATIONAL JOURNAL OF INTERDISCIPLINARY DENTISTRY". Por último, y tal vez el desafío mayor es desarrollar una estrategia que nos permita poder llegar a todos(as) los(as) investigadores de FIPP y AILARO, para que también publiquen en nuestra revista y ser capaces de incorporarnos a otros sistemas de indexación tales como Medline, PubMed, Scopus e ISI-WOS.

Jorge Gamonal Aravena Editor 